\title{
Study of output differences of two different ionization chambers for large fields used in radiotherapy
}

\author{
Ehab A. Hegazy \\ Department of basic science, Faculty of engineering, Delta University for science and technology, Mansoura, \\ Egypt
}

\begin{abstract}
Many radiotherapy centers don't pay attention to effect of ionization champers type on accuracy of quality control measurements. They use any available ionization champers in all quality control and data entry measurements ${ }^{(1,2)}$. Many studies were carried out in this field to compare different ionization champers in small fields but large fields were not completely compared before ${ }^{(3.4)}$. The aim of this work is to compare output factor in large field using two different sizes ionization champers connected to electrometer. Final out put were obtained from the farmer and smidflex dosimeter irradiated with $6 \mathrm{MV}$ photon beams. Important field side ranging from $20 \mathrm{~cm}$ to $70 \mathrm{~cm}$ side field is measured in whole body radiation ${ }^{(5,6)}$.

For all examined large field sizes a difference ranging from $1 \%$ to $5 \%$ was found when added to other calibration errors it will exceeds the acceptable margin. The largest difference was found in field side $70 \mathrm{~cm}$ this may be due to large scattering radiation
\end{abstract}

\section{Indexing terms/Keywords}

Radiotherapy, ionization chamber, large fields, whole body radiation.

\section{SUBJECT CLASSIFICATION}

Experimental Medical Physics

\section{INTRODUCTION}

Ionization chamber is used as slandered tool in absolute dose reading due to long term stability, high precision, direct readout, and relative ease of use, it consists of a wall of special material such as graphite and a small specific volume of air with a voltage applied between the wall and an electrode to collect the dose response as charge produced in the air by the ionizing radiation used in radiotherapy treatments ${ }^{(7.8)}$.

For accurate the dosimeter performance the dose should be linearly proportional to dose quantity. Characteristic dose curves for used ionization chamber should be obtained prior any measurements. However, beyond a certain dose range a non-linearity sets in. The linearity range and the non-linearity behavior depend on the type of dosimeter and its physical characteristic. $^{(9.10)}$.

The distribution of dose in a patient using the basic ideas of photon interactions with tissue alone is full of uncertainties and considered as inaccurate technique. All calculated dose distributions are therefore based on certain quantities derived from experimental radiological measurements. Experimental data is incorporated together to algorithms to set the basis of treatment to planning systems for external beam radiotherapy ${ }^{(11)}$.

\section{Material and Method}

Ionization chambers (PTW $0.6 \mathrm{~cm}^{3}$ and $0.125 \mathrm{~cm}^{3}$ ) noted as $\mathrm{x} 1$ used in this study are calibrated by General National Laboratory, Braunschweig, Germany. $0.6 \mathrm{~cm}^{3}$ farmer-type ionization chamber (Type 30013 PTW-Freiburg) noted as $\times 2.0 .125 \mathrm{~cm}^{3}$ semi flex ionization chamber Type 31010 PTW-Freiburg is a thimble chamber for use in connection with therapy dosimeters according to IEC 60731 or with the dosimeters of beam analyzers (water phantoms). All measurement held in Mansoura university hospital, faculty of medicine, department of oncology and nuclear medicine.

\section{3- Results and Discussion}

Optical density versus absorbed dose was measured to produce Characteristic curve for X1 and X2 ionization champers. Radiation beam is obtained over a wide range of absorbed dose by irradiating therapy verification film type Kodak X-Omat V. The film is exposed to radiation at the buildup depth using field size $10 \times 10 \mathrm{~cm}^{2}$ at SSD $=80 \mathrm{~cm}$. The optical density is measured using Kodak LS50 film digitizer as connected to MP3-S therapy beam analyzer system. The relation between the radiation exposures in Gy and the optical density is shown in figure 1. 


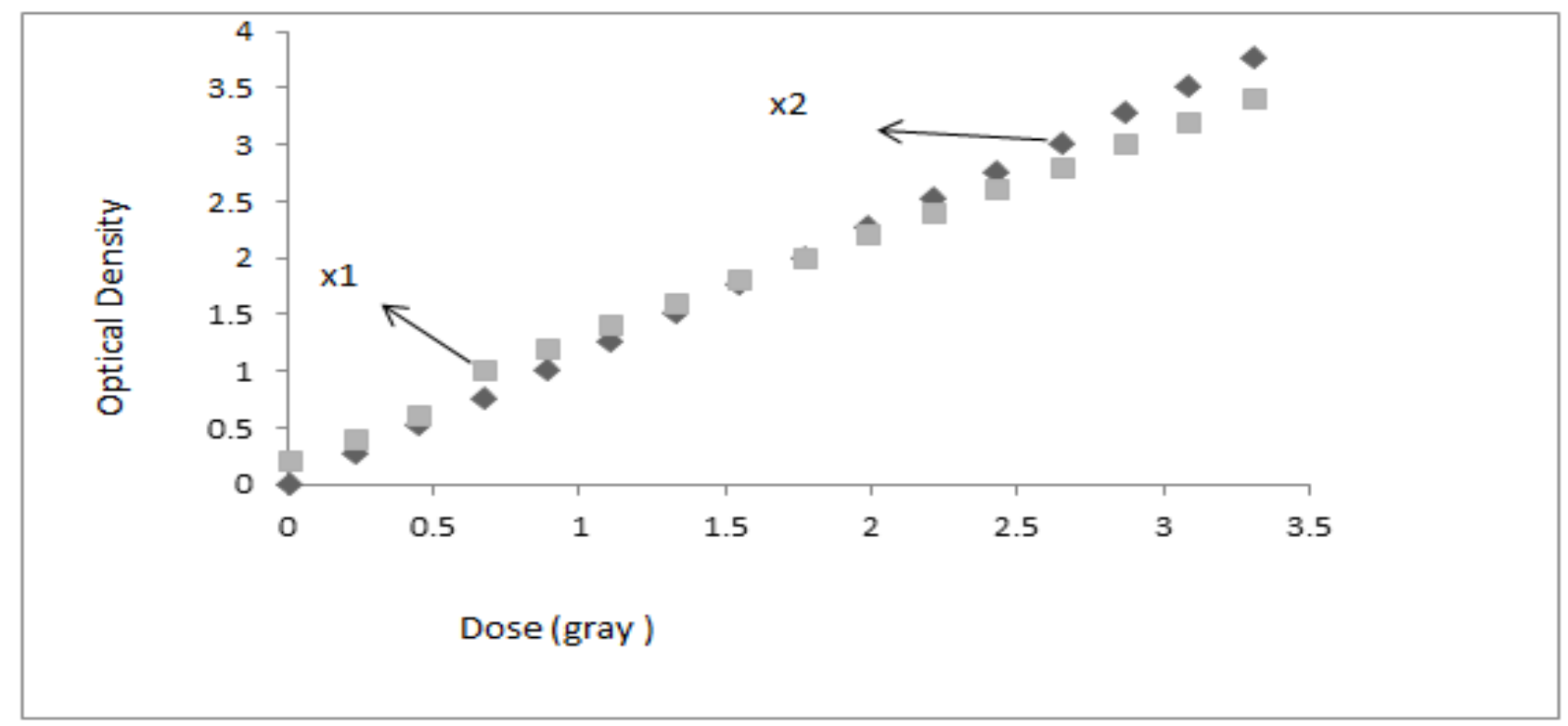

Figure 1. Relationship between optical density versus absorbed dose (Gy).

For $\mathrm{x} 1$ and $\mathrm{x} 2$ ionization champers optical density of radiographic films is optioned. Figure 1 show normal relationship between absorbed dose and optical density for used ionization chamber so they can be used in dose measurements.

All measurement are carried out under standard conditions in water phantom, and field to source distance were adjusted to reach large field as the maximum collimator opening is $40 \mathrm{~cm} \times 40 \mathrm{~cm}$.

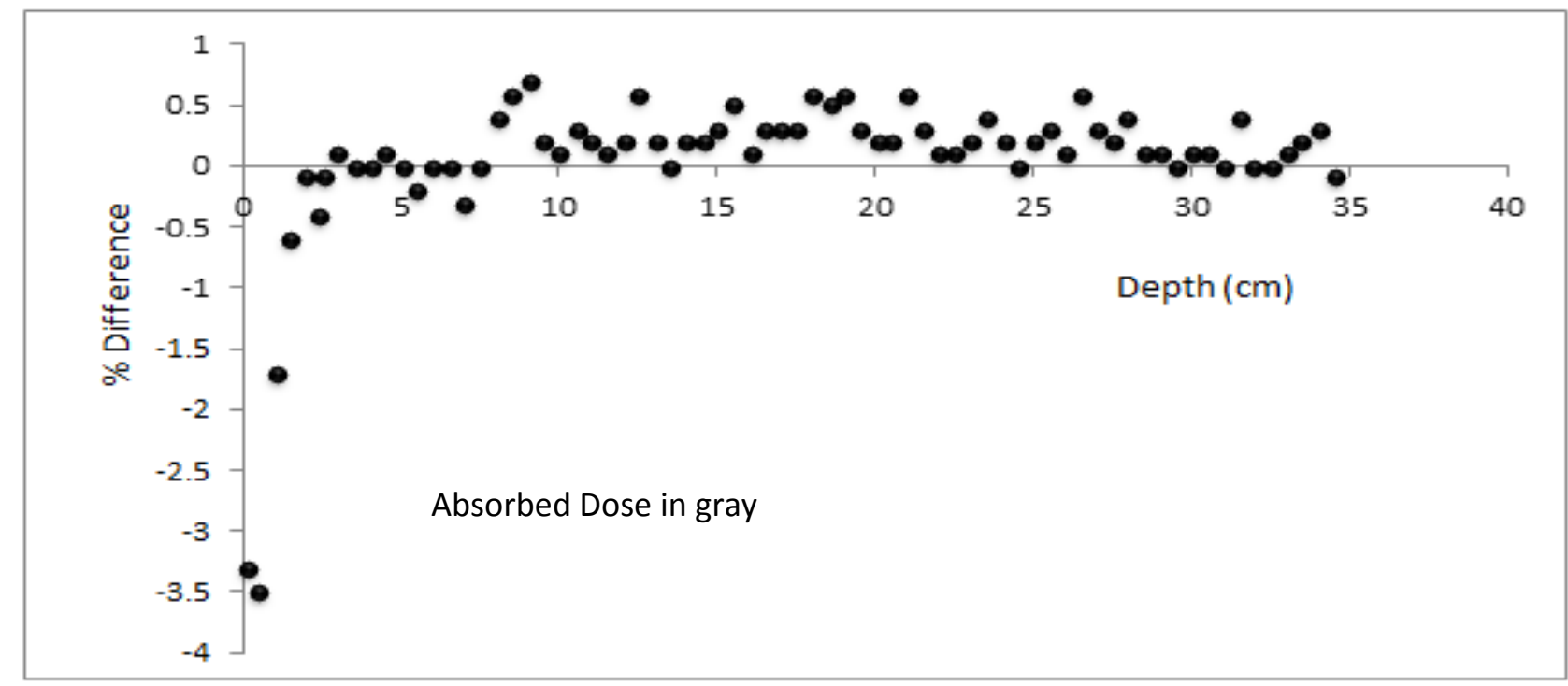

Figure 2. Measurement of output dose difference between versus depth for field size $20 \times 20 \mathrm{~cm}^{2}$.

For field size $20 \times 20 \mathrm{~cm}^{2}$ it's found that from the surface to $2.5 \mathrm{~cm}$ depth the maximum difference was $3.5 \%$ which is considered as significant difference this is due to surface perturbation and instability of chamber reading. It is noticed that difference decreases as the depth increase the difference decreased this due to more homogeneously medium .from depth $2.5 \mathrm{~cm}$ to $35 \mathrm{~cm}$ the maximum difference was less than $1 \%$. 


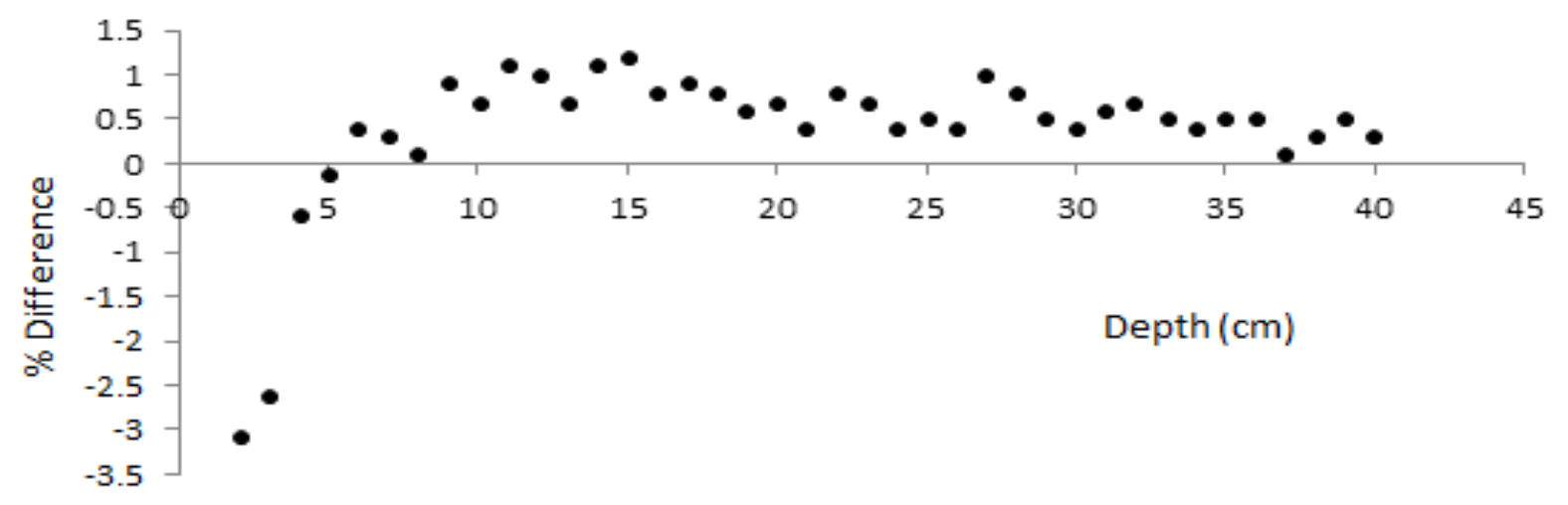

Figure 3. Measurement of output dose difference between versus depth for field size $25 \times 25 \mathbf{c m}^{2}$.

For field size $25 \times 25 \mathrm{~cm}^{2}$. It's found that from the surface to depth $2.5 \mathrm{~cm}$ the maximum difference was $3.2 \%$. From depth $2.5 \mathrm{~cm}$ to $35 \mathrm{~cm}$ the maximum difference was less than $1.5 \%$.

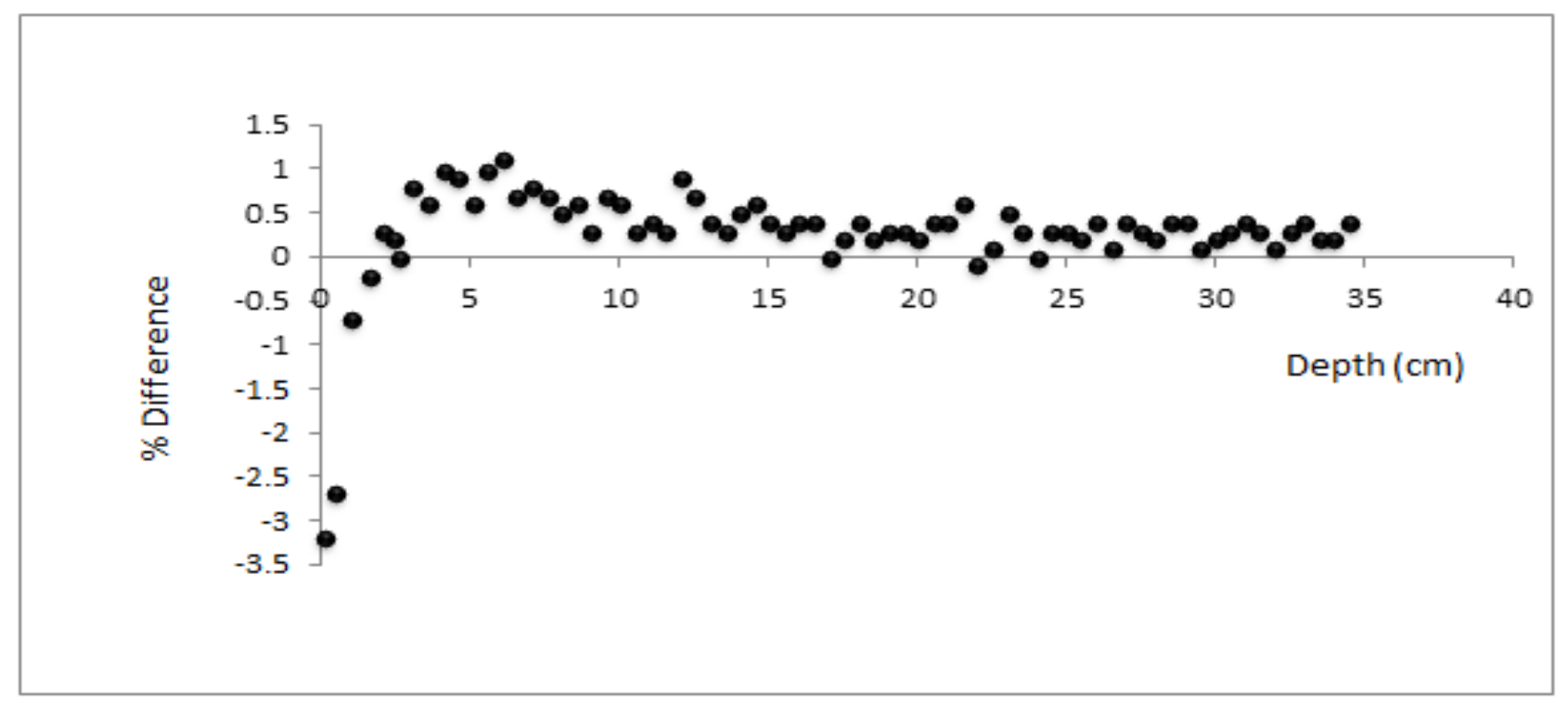

Figure 4. Measurement of output dose difference between versus depth for field size $30 \times 30 \mathrm{~cm}^{2}$.

For field size $30 \times 30 \mathrm{~cm}^{2}$. It's found that from the surface to depth $2.5 \mathrm{~cm}$ the maximum difference was $3.2 \%$.from depth $2.5 \mathrm{~cm}$ to $35 \mathrm{~cm}$ the maximum difference was less than $1.5 \%$. 


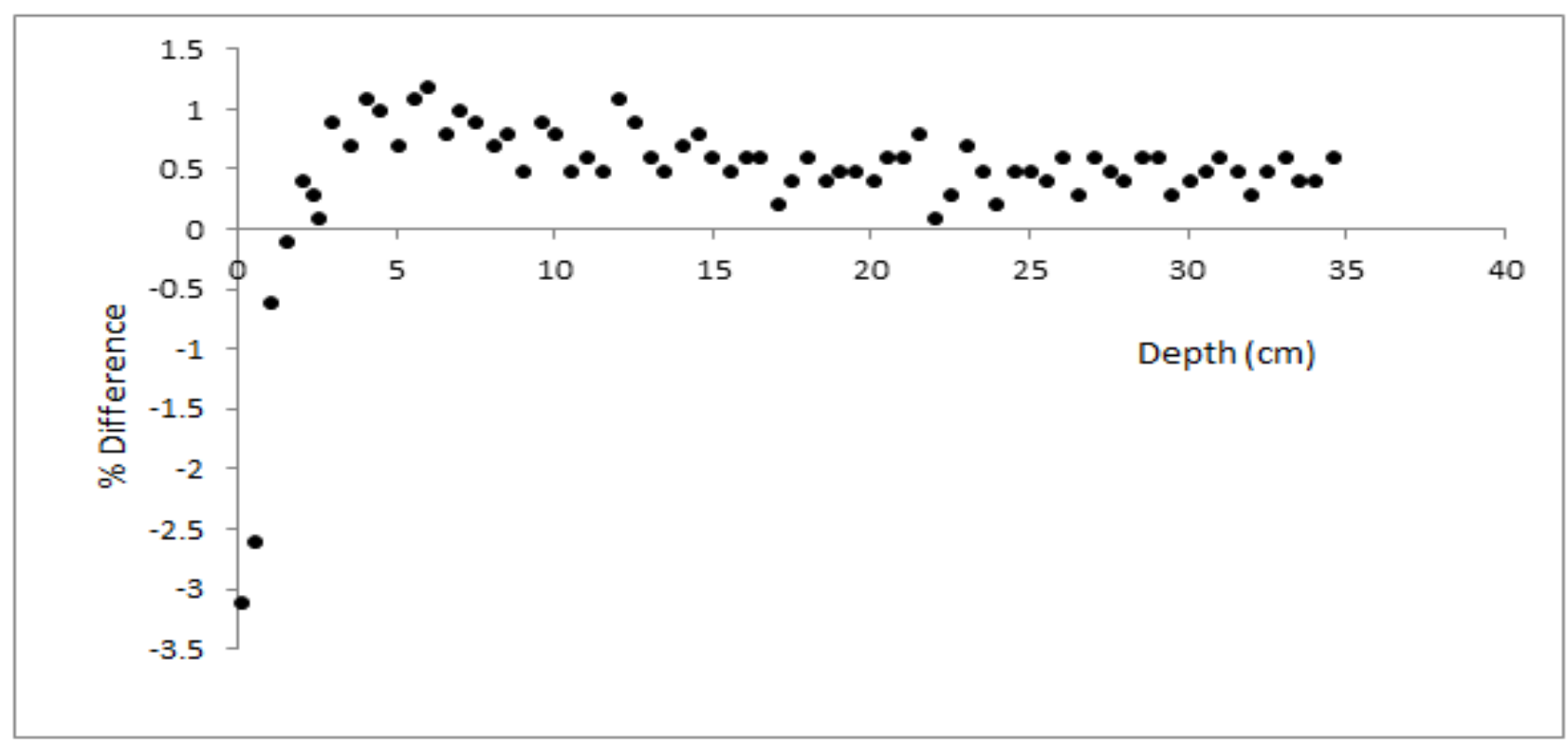

Figure 5. Measurement of output dose difference between versus depth for field size $35 \times 35 \mathrm{~cm}^{2}$.

For field size $35 \times 35 \mathrm{~cm}^{2}$. It's found that from the surface to depth $2.5 \mathrm{~cm}$ the maximum difference was $3.2 \%$. From depth $2.5 \mathrm{~cm}$ to $35 \mathrm{~cm}$ the maximum difference was less than $1.5 \%$.

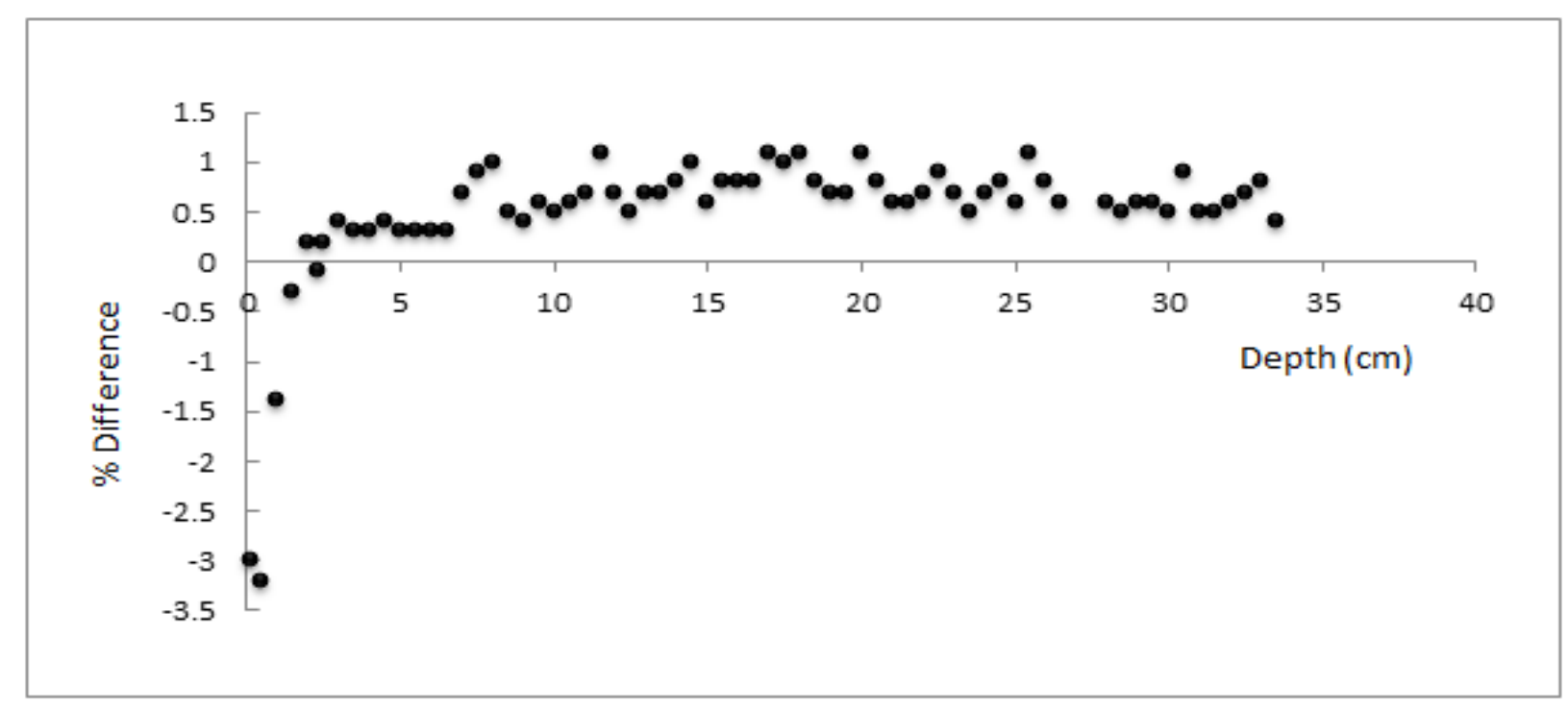

Figure 6. Measurement of output dose difference between versus depth for field size $40 \times 40 \mathrm{~cm}^{2}$.

For field size $40 \times 40 \mathrm{~cm}^{2}$. It's found that from the surface to depth $2.5 \mathrm{~cm}$ the maximum difference was $3.25 \%$. From depth $2.5 \mathrm{~cm}$ to $35 \mathrm{~cm}$ the maximum difference was less than $1.5 \%$. 


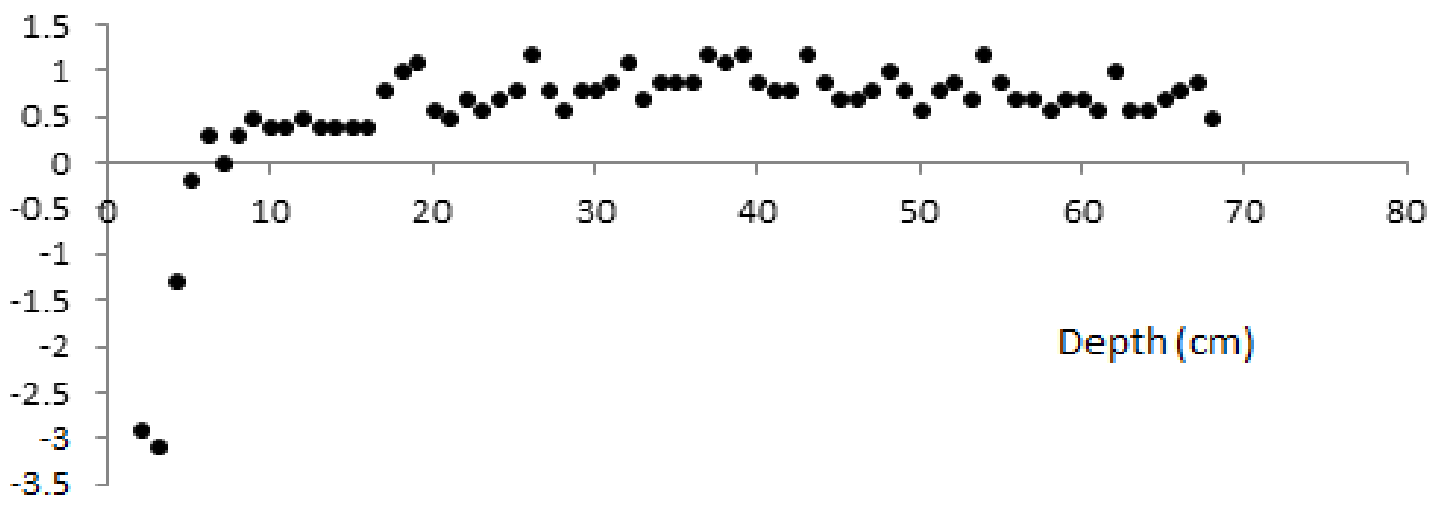

Figure 7. Measurement of output dose difference between versus depth for field size $45 \times 45 \mathrm{~cm}^{2}$.

For field size $45 \times 45 \mathrm{~cm}^{2}$. It's found that from the surface to depth $2.5 \mathrm{~cm}$ the maximum difference was $3.22 \%$. From depth $2.5 \mathrm{~cm}$ to $70 \mathrm{~cm}$ the maximum difference was less than $1.5 \%$.

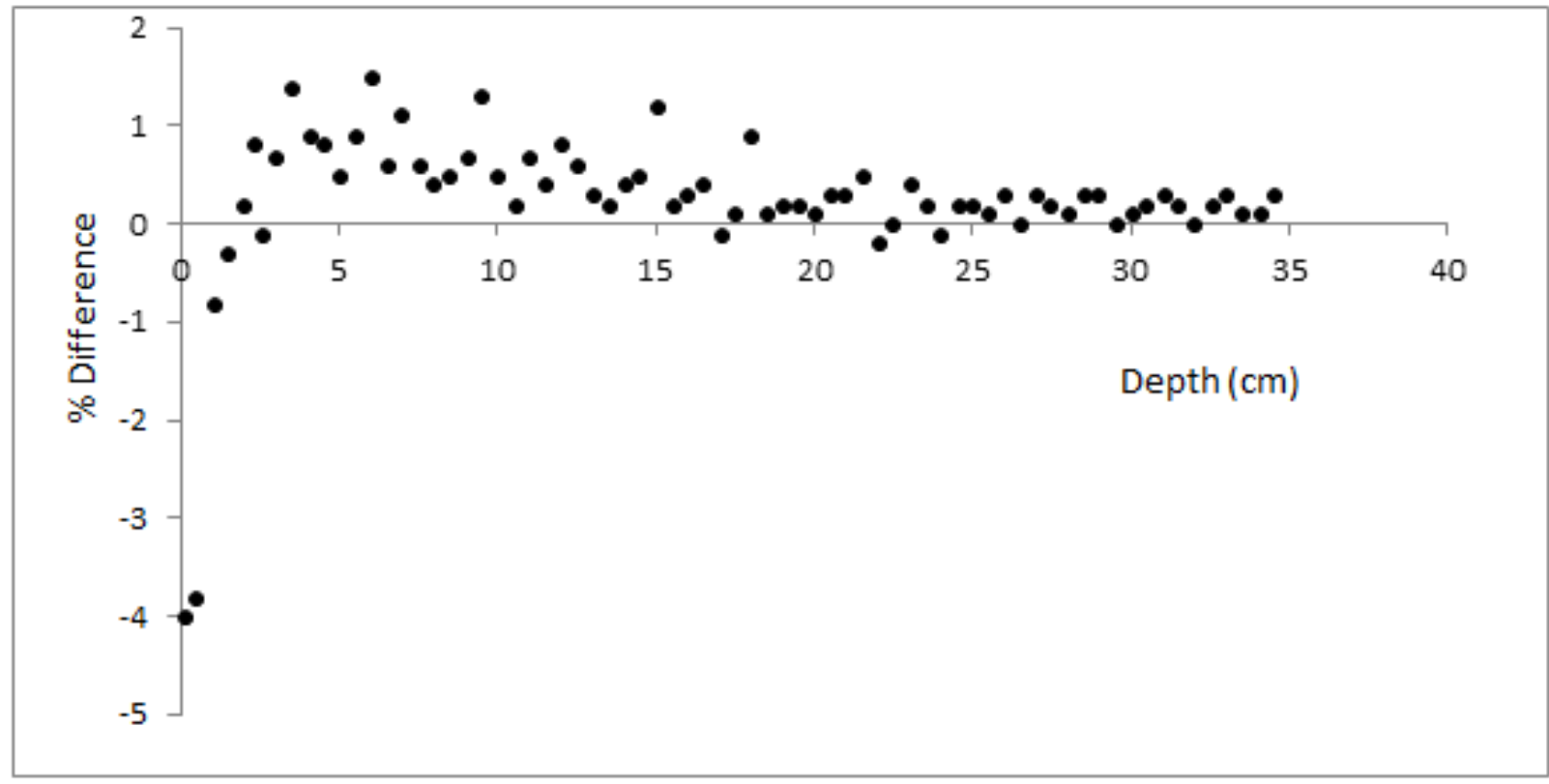

Figure 8. Measurement of output dose difference between versus depth for field size $55 \times 55 \mathrm{~cm}^{2}$. 


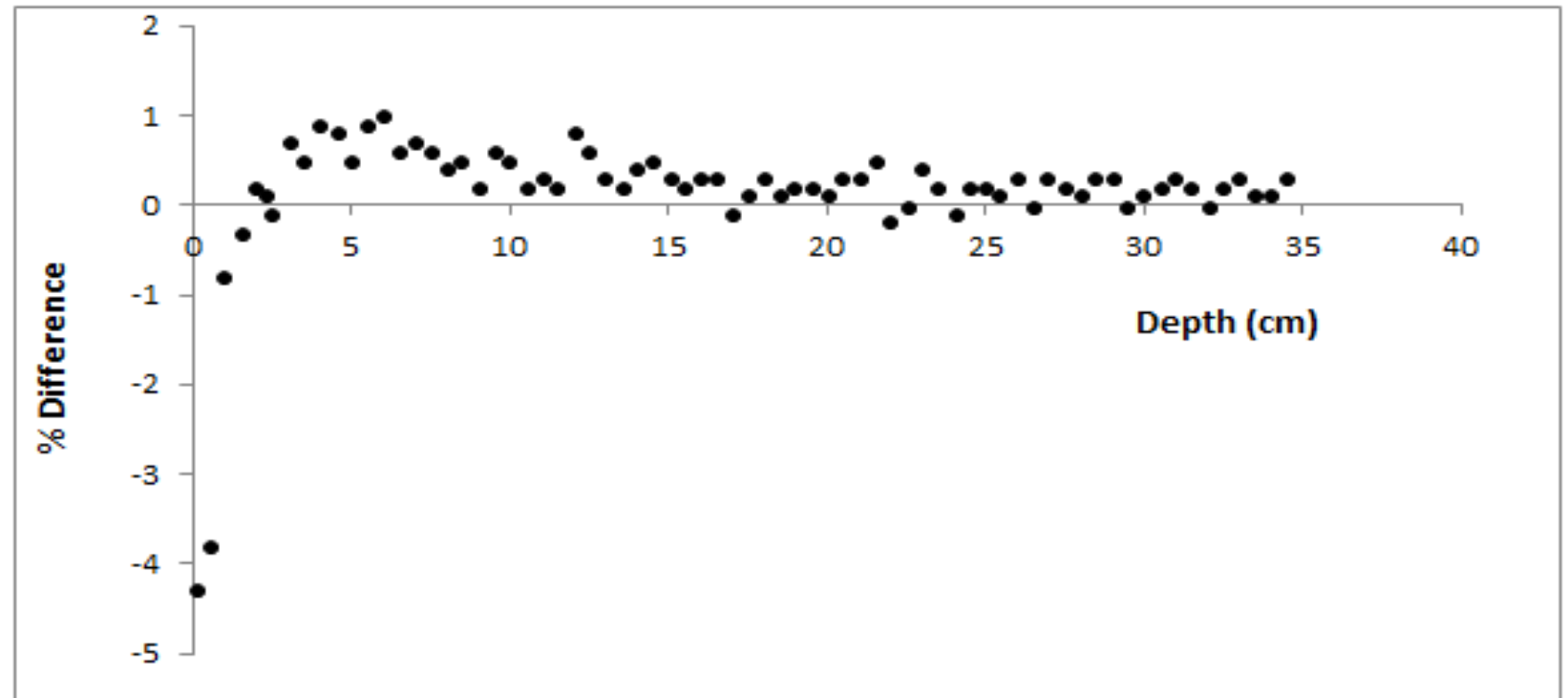

Figure 9. Measurement of output dose difference between versus depth for field size $65 \times 65 \mathrm{~cm}^{2}$.

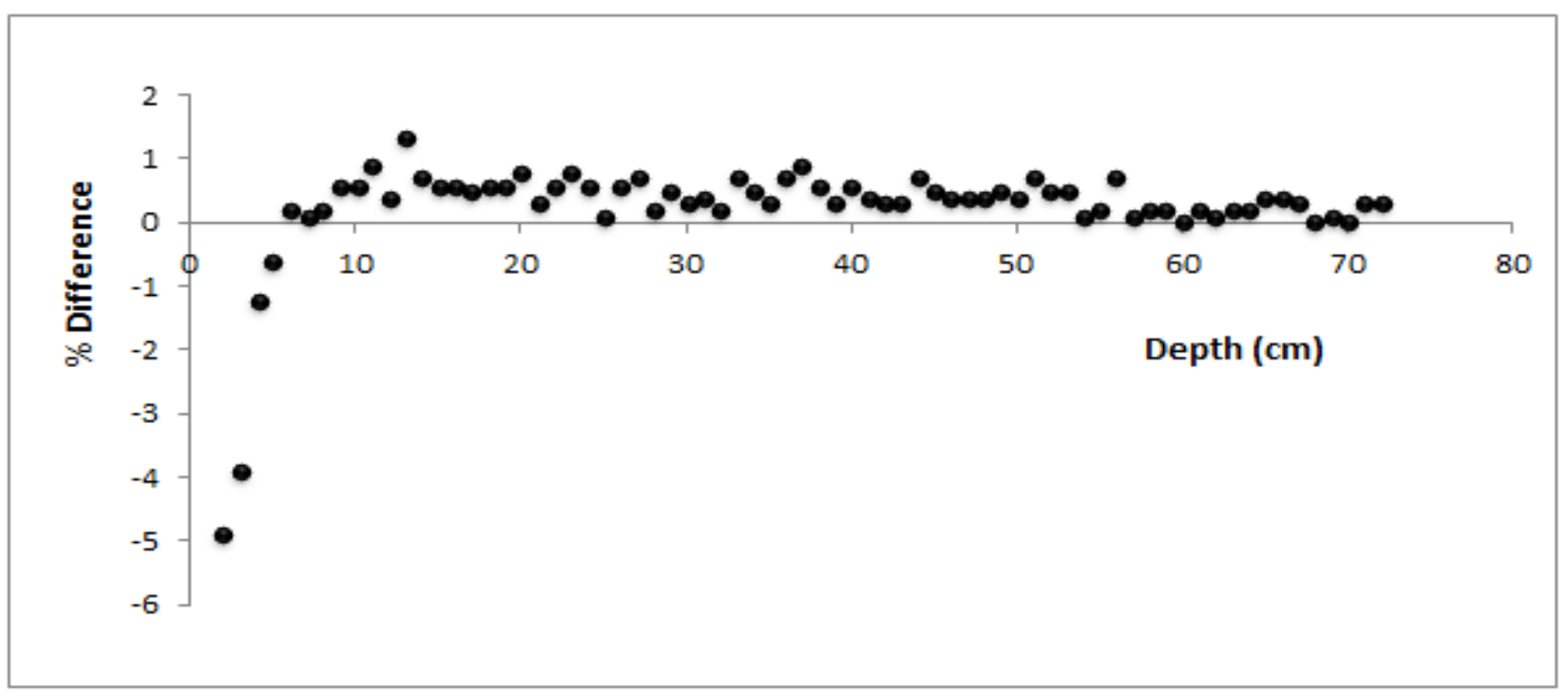

Figure 10. Measurement of output dose difference between versus depth for field size $70 \times 70 \mathrm{~cm}^{2}$.

As shown in figures 8,9 and 10 For field side 55,65 and $70 \mathrm{~cm}$ respectively the difference was increased to about $5 \%$ at the surface this may be due to more scattering radiation from large field size this may produce more accumulated radiation undetectable from planning systems and produce overdose to patient specially with skin cancer . the difference was $1.4 \mathrm{~cm}$ at deep depths.

\section{Conclusion}

For all examined large field sizes a difference ranging from $1 \%$ to $5 \%$ was found when added to other calibration errors it will exceeds the acceptable margin. The largest difference was found in field side $70 \mathrm{~cm}$ this may be due to large scattering radiation. Selection of detector type has great effects on absolute dose reading .We conclude that more attention in calibration should be done in selecting chamber especially in large radiation fields which widely used in whole body and half body irradiation.

However, it should be highlighted that we did not prefer one chamber over other one due to variation of difference from the surface to deep depths more studies should be done to study this behavior 


\section{References}

1- Baldock C, De Deene Y, Doran S, IbboC G, Jirasek A, Lepage M, McAuley KB, Oldham M, Schreiner LJ (2010) Polymer gel dosimetry. Phys Med Biol, 55:R1-63.

2- Olding T, Holmes O, Dejean P, McAuley KB, Nkongchu K, Santyr G, Schreiner LJ (2011) Small field dose deliveryevalua_ons using cone beam op_cal computed tomography-based polymer gel dosimetry. $J$ Med Phys,36:3-14.

3- Van Dyk J. The modern Technology of Radiation Oncology. Madison: Medical Physics Publishing; 1999. p. 64162.

4- Vrtar M. Fizikalni aspekti tehnike ozraèenja cijelog tijela (TBI). (Physical aspects of total body irradiation technique (TBI). Zbornik predavanja dru'tvaza mernu tehniku Srbije - Sekcija za merenja u radioterapiji. Belgrade: 1988. p. 209-30.

5- INTERNATIONAL ATOMIC ENERGY AGENCY (IAEA), "Calibration of Dosimeters used in Radiotherapy: A manual sponsored by the IAEA and WHO", IAEA Technical Report Series, TRS-374, IAEA, Vienna, Austria (1994).

6- INTERNATIONAL ATOMIC ENERGY AGENCY (IAEA), "The use of plane parallel ionisation chambers in high energy electron and photon beams", IAEA Technical Report Series, TRS-381, IAEA, Vienna, Austria (1997).

7- INTERNATIONAL ATOMIC ENERGY AGENCY (IAEA), "Absorbed dose determination in external beam radiotherapy: An international code of practice for dosimetry based on standards of absorbed dose to water", IAEA Technical Report Series, TRS-398, IAEA, Vienna, Austria (2000)

8- INTERNATIONAL ORGANIZATION FOR STANDARDIZATION (ISO), "Guide to expression of uncertainty in measurement", ISO, Geneva, Switzerland (1992).

9- KHAN, F.M., "The physics of radiation therapy", Williams and Wilkins, Baltimore, Mary-land, U.S.A. (1994).

10- KLEVENHAGEN, S.C., "Physics and dosimetry of therapy electron beams", Medical Physics Publishing, Madison, Wisconsin, U.S.A. (1993).

11-VAN DYK, J. (editor), "Modern technology of radiation oncology: A compendium for medical physicists and radiation oncologists", Medical Physics Publishing, Madison, Wisconsin, U.S.A. (1999). Forman, G. 2003. An extensive empirical study of feature selection metrics for text classification. J. Mach. Learn. Res. 3 (Mar. 2003), 1289-1305.

\section{Author' biography}

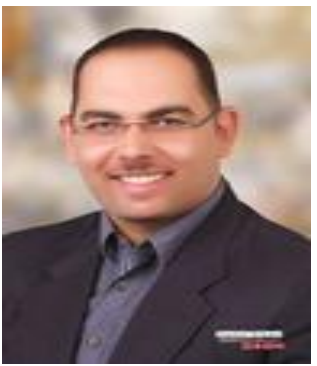

Dr. Ehab Abdelreheem Hegazy.

Working as lecturer of physics, Faculty of engineering Delta University for science and technology.

Egypt.

ehabhegazy99@yahoo.com 